\title{
Large decline in injecting drug use in Amsterdam, 1986-1998: explanatory mechanisms and determinants of injecting transitions
}

\author{
E J C van Ameijden, R A Coutinho
}

\begin{abstract}
Objectives-To study community wide trends in injecting prevalence and trends in injecting transitions, and determinants. Design-Open cohort study with follow up every four months (Amsterdam Cohort Study). Generalised estimating equations were used for statistical analysis.

Setting-Amsterdam has adopted a harm reduction approach as drug policy.

Participants-996 drug users who were recruited from 1986 to 1998 , mainly at methadone programmes, who paid 13620 cohort visits.

Main results-The prevalence of injecting decreased exponentially (66\% to $36 \%$ in four to six monthly periods). Selective mortality and migration could maximally explain $33 \%$ of this decline. Instead, injecting initiation linearly decreased (4.1\% to $0.7 \%$ per visit), cessation exponentially increased $(10.0 \%$ to $17.1 \%)$, and relapse linearly decreased $(21.3 \%$ to $11.8 \%$ ). Non-injecting cocaine use (mainly pre-cooked, comparable to crack) and heroin use strongly increased. Trends were not attributable to changes in the study sample.

Conclusions-Harm reduction, including large scale needle exchange programmes, does not lead to an increase in injecting drug use. The injecting decline seems mainly attributable to ecological factors (for example, drug culture and market). Prevention of injecting is possible and peer-based interventions may be effective. The consequences of the recent upsurge in crack use requires further study.

(F Epidemiol Community Health 2001;55:356-363)
\end{abstract}

(Netherlands Institute of Mental Health and Addiction), Utrecht, the Netherlands E J C van Ameijden

Municipal Health Service, Amsterdam, the Netherlands R A Coutinho

Correspondence to: Dr van Ameijden, Trimbos Institute, Department of Monitoring and

Epidemiology, PO Box 725, 3500 AS Utrecht, the

Netherlands (eameijden@ trimbos.nl)

Accepted for publication 9 January 2001
Prevention of initiation into injecting drug use may be difficult ${ }^{17}$ as cultural (for example, norms, attitudes) and ecological (for example, drug market, drug policy) factors seem important determinants. ${ }^{19-22}$ Whereas in several cities injecting behaviour was reported to decline, such as New York, ${ }^{23}{ }^{24}$ cities in Spain, ${ }^{21}{ }^{22}$ and Edinburgh, ${ }^{25}{ }^{26}$ injecting is increasing in other places, for example, in Asia. ${ }^{127}$ Many previous studies were serial cross sectional surveys, and trends in the prevalence of injecting among drug users might be observed in the absence of individual behaviour changes (for example, injecting initiation and cessation). This can be attributable to selective depletion of injectors in an aging cohort of drug users because of mortality and migration.

Amsterdam is an interesting city to study community wide and individual trends in injecting behaviour because of its harm reduction approach. ${ }^{28}$ As an estimated $60 \%$ of opioid users attend one of the low, medium or high threshold methadone programmes in Amsterdam, ${ }^{29}$ these programmes may have had an impact on trends in injecting use, methadone treatment being associated with reduced drug injecting. ${ }^{11} 1230$ Needle and syringe availability is high and there are no needle prescription or possession laws. ${ }^{31}$ Needles and syringes can be bought at pharmacies, certain shops and vending machines, and Amsterdam has the oldest needle exchange programmes (NEPs) worldwide (start 1984). They are low threshold and large scale (no limits to number of needles exchanged, long opening hours, 13 locations). Although several studies indicated that NEPs do not lead to an increase in injecting drug use, ${ }^{12} 23243132$ these often had short follow up, the majority of NEPs being implemented recently, on a smaller scale, and with more restrictions. Other interventions in Amsterdam include health education, HIV counselling and testing (since 1986), and outreach activities.

The estimated number of opioid users in Amsterdam remained fairly stable at an estimated 6000, although the mean age strongly increased..$^{33}$ In 1990 there were about 2500 current injectors. ${ }^{34}$ As in other cities, injecting seems on the decline, as the number of needles exchanged halved and, among current injectors, the mean age and duration of injecting strongly increased. ${ }^{35}$ It is unknown to what extent these trends are the result of individual transitions in injecting versus selection mechanisms. The Amsterdam heroin epidemic started in the 1970 s resulting in a possible 
cohort effect with selective mortality. Also, a "repatriation policy" was adopted; drug users with a foreign nationality were stimulated to go to their country of origin, injecting behaviour being more prevalent among foreigners (70\%) than among Dutch users $(40 \%$ among native Dutch users, and 5\% among Surinamese and Antillean users). ${ }^{34}$

The main study questions are: (1) what are the trends in the prevalence of current injecting and in the incidences of initiation of injecting, cessation of injecting, and relapse into injecting; (2) to what extent can the trend in the prevalence of current injecting be explained by selection mechanisms; and (3) what are determinants of the four outcomes under question 1. As part of the Amsterdam Cohort Studies, long term follow up is available (1986-1998) with high statistical power and determinants of transitions in injecting behaviour have hardly been established.

\section{Methods}

In December 1985 an open cohort study (continuous recruitment of new participants) among drug users was started in Amsterdam. ${ }^{36}$ Briefly, recruitment is mainly via methadone posts, including a special clinic for addicted prostitutes. Participation is voluntary and with informed consent. Participants are asked to return every four months for follow up visits. At every visit, blood is drawn and specially trained nurses administer a standardised questionnaire. At intake, questions regarding current behaviour refer to the period of six months preceding the intake, while at follow up visits these questions refer to the period between present and preceding visit. Participants receive HIV test results together with HIV and other counselling. From January 1986 to December 1998, 1294 drug users were included. For the purpose of this study, all 996 participants were selected who paid at least one follow up visit; 13620 visits were analysed. The main determinant for loss to follow up is having a foreign nationality.

The main outcomes studied were prevalence of current injecting, incidence of initiation of injecting (injecting at least once, among drug users without injecting history), incidence of cessation of injecting (a non-injecting period of at least four months, among current injectors), and incidence of relapse into injecting (injecting at least once, among former drug injectors who stopped injecting for four months or more). Incidences are expressed as percentage per visit, the mean interval between visits being 5.3 months. For all analyses, study visits were the unit of analysis; one person can be multiple times at risk for cessation and relapse. To adjust for correlation between multiple measurements of the same individual, generalised estimating equations (GEE) were used for statistical analyses. ${ }^{37}$ As the correlation between injecting behaviour at cohort visits within one person was comparable between visits close and far from each other in time, an exchangeable autocorrelation structure was used.

To study trends over time, the dichotomous outcomes were modelled with GEE using an identity (linear) link function with a binomial mean-variance relations - that is, an additive model. In this model the main and possibly polynomial effect estimates of calendar year reflect linear and exponential time trends, respectively (a logistic link function would inherently assume a non-linear time trend). As percentages in additive models can be estimated to be $<0 \%$ and $>100 \%$, special attention was paid to the fit of the models by comparison of (1) observed percentages, (2) predicted percentages using model coefficients and (3) predicted values based on GEE output: no systematic differences were present. Testing was done two sided and $\mathrm{p}$ values $<0.05$ were considered significant.

Various subanalyses were performed to study exploratory mechanisms for the observed trends. Firstly, trends over time may be explained by changes in the composition of the study population; trends were therefore statistically adjusted for changes in sociodemographics (see below, set 1). Trends were also adjusted for "number of cohort visit" (coded from 0 to 5, representing visit $1,2-3,4-6,7-12,13-20$, $>20$, as a categorical variable), indicating a possible preventive effect of the study itself on injecting behaviour attributable to the counselling component, and a possibly increasing unwillingness to admit injecting at subsequent cohort visits (socially desirable answering). No adjustment was made for current behaviours (set 2), as this can result in "overadjustment" as several current behaviours can be intermediate variables in the causal pathway.

Secondly, the trend in the prevalence of current injecting may be attributable to selective drop out, especially because of mortality and migration. Two subanalyses were performed to estimate the maximum explanatory potential of such factors: (1) for participants lost to follow up before the study end point (December 1998) it was simulated that they attended every four months until this end point with continuation of the injecting behaviour reported at the last cohort visit, and (2) the trend in current injecting was calculated only for participants who were not lost-that is, who had a last cohort visit in 1997-98.

Independent determinants for the four main outcomes were also studied using GEE. A logistic link function was used to be able to provide odds ratios (ORs). With regard to the prevalence of current injecting, information on time dependent determinants was used at the same visit at which current injecting was reported. With regard to individual injecting transitions, the time dependent current behaviours were measured at the last cohort visit preceding the visit at which the outcome was measured, to ensure that exposure always preceded the outcome. All univariately significant variables were entered in a multivariate model, after which backward selection was applied. Categories of covariates were collapsed given similar effects. Ordinal variables showing a dose-effect relation were put into the model as linear effects. Selection of cohort visits with an interval between visits of less than six months ( $89 \%$ of all visits) gave similar results. 
Table 1 Trends in sociodemographic variables, using 13620 visits of 996 drug users in the Amsterdam Cohort Study

\begin{tabular}{|c|c|c|c|c|c|c|c|}
\hline & $86-88$ & $89-90$ & $91-92$ & $93-94$ & $95-96$ & $97-98$ & $p$ Value \\
\hline Number cohort visits & 1658 & 1863 & 2110 & 2554 & 2772 & 2663 & \\
\hline Female $(\%)$ & 46 & 41 & 39 & 37 & 35 & 33 & $\star \star \star$ \\
\hline Age & 29.7 & 32.0 & 34.1 & 35.6 & 37.1 & 38.7 & $\star \star \star$ \\
\hline Nationality & & & & & & & $\star \star \star$ \\
\hline Dutch (\%) & 74 & 74 & 76 & 78 & 80 & 81 & \\
\hline German (\%) & 18 & 16 & 13 & 10 & 8 & 7 & \\
\hline Ethnicity & & & & & & & $\star \star \star$ \\
\hline West European (\%) & 89 & 90 & 88 & 84 & 82 & 82 & \\
\hline Surinam/Antillean (\%) & 5 & 5 & 6 & 9 & 12 & 12 & \\
\hline Left school age <16 (\%) & 60 & 56 & 57 & 56 & 56 & 56 & $\star \star$ \\
\hline HIV seropositive (\%) & 36 & 37 & 36 & 33 & 29 & 26 & $\star \star \star$ \\
\hline History of injecting (\%) & 89 & 89 & 87 & 86 & 82 & 79 & $\star \star \star$ \\
\hline Years since onset injecting & 9.4 & 10.9 & 12.4 & 13.6 & 14.8 & 16.3 & $\star \star \star$ \\
\hline Age start injecting $\dagger$ & 20.3 & 21.0 & 21.7 & 22.4 & 22.7 & 22.7 & $\star$ \\
\hline Homelessness $(\%) \ddagger$ & - & 16 & 17 & 17 & 17 & 18 & NS \\
\hline Prostitution (\%) $\ddagger$ & 29 & 20 & 14 & 14 & 12 & 10 & $\star \star \star$ \\
\hline Daily methadone $(\%) \ddagger$ & 83 & 73 & 72 & 70 & 70 & 66 & $\star \star \star$ \\
\hline
\end{tabular}

$\star, p<0.05 ; \star \star, p<0.01 ; \star \star \star, p<0.001$; GEE was used for statistical analysis, using a linear link function. †Only at visits of participants with history of injecting. $\ddagger$ Current behaviour - that is, in the preceding six months or since the previous cohort visit.

Variable set 1 consisted of sociodemographical variables: gender, age $(<30,30-35,35-40$, $40+$ ), nationality (Dutch, German, other), ethnicity (West European, Surinamese/Antillean, other), school drop out before the age of 16 , history of injecting, years since onset of injecting $(<2,2-6,6-13,13-21,21+)$, age at start injecting $(<18,18-24,24+)$, years since cessation of injecting $(<1,1-2,2-4,4-8,8+)$, HIV serostatus, and having received an AIDS diagnosis. Sociodemographics reflecting current behaviours were: prostitution, homelessness, and frequency of methadone use (none, <daily, daily; this is a valid surrogate for frequency of attending methadone programmes ${ }^{38}$ ).

All variables in set 2 are current behaviours: alcohol use (none, 1-4 units/day, $>4$ units), tranquiliser use (none, <daily, daily), noninjecting heroin and cocaine use (none, <daily, daily), type of drug mainly injected (heroin, cocaine, speedballs, other), frequency of injecting (<daily, daily, >daily), multiple needle use (none, 2-4 times injecting per needle, $>4$ times), percentage of new needles obtained via the needle exchange programmes $(0 \%, 1-99 \%$,

Table 2 Trends in injecting and non-injecting drug use behaviours, using 13620 visits of 996 drug users in the Amsterdam Cohort Study

\begin{tabular}{|c|c|c|c|c|c|c|c|c|}
\hline & $86-88$ & $89-90$ & $91-92$ & $93-94$ & $95-96$ & $97-98$ & $Y r$ & $Y r^{\star} Y r$ \\
\hline \multicolumn{9}{|l|}{ Injecting status (\%) } \\
\hline never & 11 & 11 & 13 & 14 & 18 & 21 & & \\
\hline stopped & 22 & 26 & 28 & 31 & 35 & 42 & & \\
\hline current & 66 & 64 & 59 & 55 & 47 & 36 & NS & $\star \star$ \\
\hline \multicolumn{9}{|l|}{ Transitions injecting: (\%)† } \\
\hline initiation & 4.1 & 5.1 & 2.8 & 1.1 & 1.1 & 0.7 & $\star$ & NS \\
\hline cessation & 10.0 & 10.2 & 10.1 & 11.0 & 13.3 & 17.1 & NS & 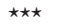 \\
\hline relapse & 21.3 & 20.1 & 19.3 & 16.9 & 13.4 & 11.8 & $\star \star \star$ & NS \\
\hline \multicolumn{9}{|l|}{ Injecting behaviours: $(\%) \ddagger$} \\
\hline Main type: heroin & 20 & 21 & 20 & 17 & 22 & 24 & \multirow{4}{*}{$\star \star$} & \multirow{4}{*}{ NS } \\
\hline \multirow{3}{*}{ Main type: } & 9 & 12 & 10 & 15 & 20 & 18 & & \\
\hline & 61 & 56 & 60 & 59 & 51 & 45 & & \\
\hline & 10 & 11 & 10 & 9 & 7 & 13 & & \\
\hline$\geqslant 2$ injections/day & 39 & 36 & 32 & 31 & 25 & 22 & $\star \star \star \star$ & NS \\
\hline All needles at exchange & 57 & 65 & 66 & 75 & 73 & 73 & 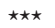 & $\star \star \star \star$ \\
\hline \multicolumn{9}{|l|}{ Non-injecting use: $(\%)$} \\
\hline \multirow[t]{2}{*}{ heroin: } & 34 & 32 & 33 & 36 & 43 & 42 & \multirow[t]{2}{*}{$\star \star \star$} & \multirow[t]{2}{*}{$\star \star \star$} \\
\hline & 27 & 19 & 15 & 18 & 20 & 19 & & \\
\hline \multirow[t]{2}{*}{ cocaine: } & 30 & 28 & 19 & 31 & 38 & 48 & \multirow[t]{2}{*}{$\star \star \star$} & \multirow[t]{2}{*}{$\star \star \star$} \\
\hline & 14 & 10 & 9 & 8 & 10 & 14 & & \\
\hline tranquilisers & 44 & 28 & 33 & 32 & 35 & 43 & $\star \star \star \star$ & $\star \star \star \star$ \\
\hline$>4$ units alcohol/day & 22 & 18 & 19 & 23 & 21 & 20 & NS & NS \\
\hline
\end{tabular}

Yr, $\mathrm{p}$ value effect calendar year; $\mathrm{Yr}^{\star} \mathrm{Yr}$, quadratic effect calendar year; ${ }^{\star}, \mathrm{p}<0.05 ;{ }^{\star \star}, \mathrm{p}<0.01 ;{ }^{\star \star \star}$, $\mathrm{p}<0.001$; GEE was used for statistical analysis, using a linear link function. †Expressed as percentage per visit at risk, see methods. $\ddagger$ Only at visits at which participants reported current injecting.
$100 \%)$, and type of steady sexual partner (none, currently injecting, stopped injecting, no injecting history).

\section{Results}

From January 1986 to December 1998, 996 drug users were recruited who paid at least one follow up visit, totalling 13620 visits. The mean number of months between consecutive visits was 5.3 ; for $11 \%$ of visits this period exceeded six months, and for only $3 \%$ one year. The changes in the sociodemographics are shown in table 1. For a sound interpretation: the proportion of visits paid by women and current prostitutes declined because of selective recruitment via the STD clinic for drug using prostitutes in the early years, and the percentage HIV positive decreased only because selective loss to follow up of foreigners who have a higher HIV prevalence, Surinamese and Antillean participants having a Dutch nationality.

The four main outcome variables all exhibit favourable and significant trends. From 1986-88 to 1997-98, the prevalence of current injecting declined from $66 \%$ to $36 \%$, the incidence of injecting initiation declined sixfold, from $4.1 \%$ to $0.7 \%$ per visit, injecting cessation almost doubled, from $10.0 \%$ to $17.1 \%$ per visit, and relapse into injecting nearly halved, from $21.3 \%$ to $11.8 \%$ (table 2 ). Given the small numbers of initiators, cessation and relapse almost completely determine the declining trend in injecting prevalence. With regard to the prevalence of current injecting, the quadratic effect of calendar year is significant; that is, the decline is increasing. For injecting cessation, the quadratic effect means that the trend significantly exceeds a linear increase. The decreases in initiation and relapse rates are linear.

The high incidence of injecting transitions shows that injecting is not a stable behaviour. This is supported by the finding that of 800 participants who paid at least five cohort visits, $25 \%$ did never inject while attending the cohort study, $21 \%$ reported injecting at every cohort visit, and $54 \%$ reported one or more changes in current injecting.

At visits at which drug users reported current injecting use, there are also significant changes in injecting behaviours (table 2). As main type of drug, injection of speed balls decreased while injecting cocaine alone increased. Furthermore, the injecting frequency has declined, both among needle exchange programme attenders and non-attenders (data not shown). Use of the needle exchange programmes initially increased, after which this trend became significantly weaker and reached a plateau in 1993.

With regard to trends in non-injecting drug use, three variables showed a U shaped pattern (both linear and quadratic effects of calendar year were significant). Current heroin, cocaine and tranquiliser use first decreased significantly, after which there was a significant increase (table 2). Figure 1 shows that, for non-injecting heroin and cocaine use, this $U$ shaped pattern exists both at visits at which 


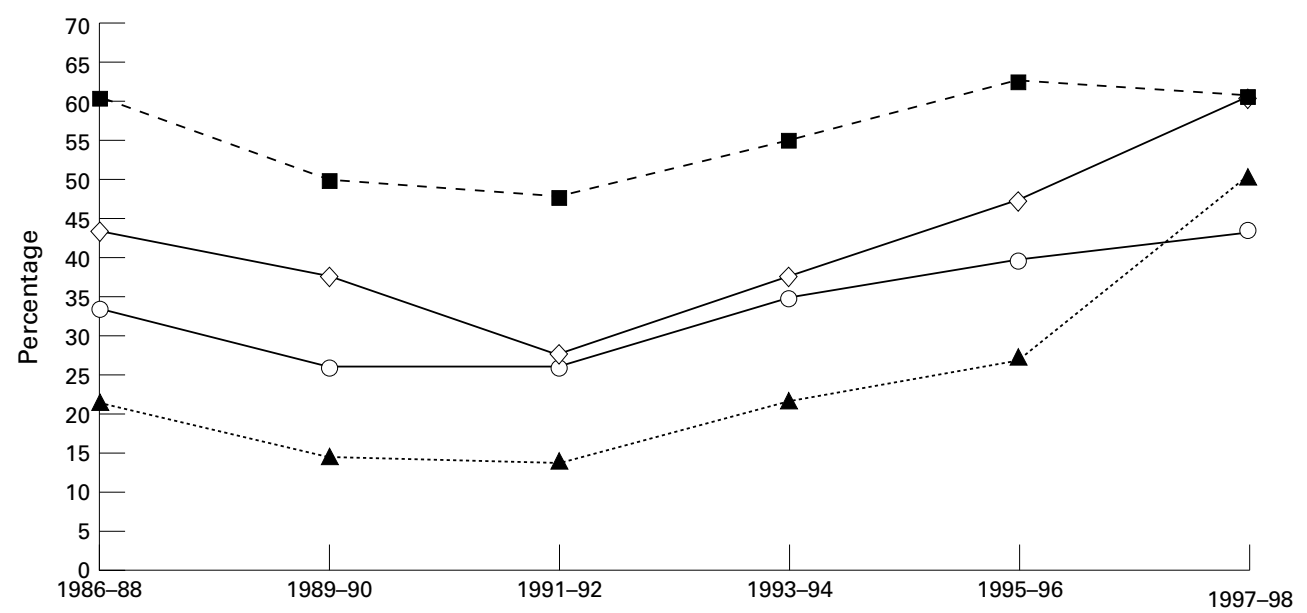

Figure 1 Trends in non-injecting drug use by current injecting among 996 drug users participating in the Amsterdam Cohort Study.

current and no current injecting use was reported. Also, cocaine use has increased stronger than heroin use in recent years, cocaine use presently being at least as prevalent as heroin use. Alcohol use did not change over time (table 2).

Table 3 Independent determinants of the prevalence of current injecting and the incidence of injecting transitions, using 13620 visits of 996 drug users in the Amsterdam Cohort Study

\begin{tabular}{|c|c|c|c|c|}
\hline & $\begin{array}{l}\text { Current injecting } \\
\text { OR }\end{array}$ & $\begin{array}{l}\text { Initiation } \\
\text { OR }\end{array}$ & $\begin{array}{l}\text { Cessation } \\
\text { OR }\end{array}$ & $\begin{array}{l}\text { Relapse } \\
\text { OR }\end{array}$ \\
\hline Year† & 1.17 & $0.57^{\star}$ & 0.71 & $0.80^{\star}$ \\
\hline Year ${ }^{\star}$ Year $\dagger$ & $0.96^{\star \star \star}$ & - & $1.05^{\star \star}$ & - \\
\hline Female & $0.64^{\star \star \star}$ & - & - & - \\
\hline Non-West European ethnicity & $0.23^{\star \star \star}$ & $0.32^{\star}$ & $1.60^{\star \star}$ & - \\
\hline Non-Dutch nationality & $1.95^{\star \star \star}$ & - & - & - \\
\hline Age $\ddagger$ & - & $0.61^{\star}$ & - & $0.85^{\star}$ \\
\hline Duration of injecting $\ddagger$ & NA & NA & - & $1.14^{\star}$ \\
\hline HIV positive & $1.40^{\star \star}$ & - & - & - \\
\hline Duration stopped injecting $\ddagger$ & NA & NA & NA & $0.81^{\star \star \star}$ \\
\hline \multicolumn{5}{|l|}{ Current behaviours: $₫$} \\
\hline \multicolumn{5}{|l|}{ Non-injecting heroin use } \\
\hline$<$ daily & 0.97 & 3.48 & $1.34^{\star \star \star}$ & - \\
\hline daily & $0.80^{\star \star}$ & $7.13^{\star \star}$ & $1.68^{\star \star \star}$ & - \\
\hline \multicolumn{5}{|l|}{ Non-injecting cocaine use } \\
\hline$<$ daily & $0.81^{\star \star \star}$ & - & - & - \\
\hline daily & 0.91 & - & - & - \\
\hline \multicolumn{5}{|l|}{ Tranquiliser use } \\
\hline$<$ daily & $1.33^{\star \star \star}$ & 2.44 & - & $1.40^{\star}$ \\
\hline daily & $1.22^{\star \star}$ & $3.47^{\star}$ & - & 0.98 \\
\hline Prostitution & $1.63^{\star \star \star}$ & - & - & - \\
\hline \multicolumn{5}{|l|}{ Steady sexual partner } \\
\hline none & 1 & 1 & 1 & 1 \\
\hline currently injecting & $1.56^{\star \star \star}$ & $3.35^{\star}$ & $0.70^{\star \star}$ & 1.17 \\
\hline stopped injecting & $0.58^{\star \star \star}$ & 2.40 & 1.22 & 0.87 \\
\hline never injected & $0.66^{\star \star \star}$ & 0.89 & $1.22^{\star}$ & $0.67^{\star \star \star}$ \\
\hline Daily methadone & $0.76^{\star \star \star}$ & - & - & - \\
\hline AIDS diagnosis & - & - & $1.80^{\star \star}$ & - \\
\hline \multicolumn{5}{|l|}{ Needles via exchange } \\
\hline none & NA & NA & 1 & NA \\
\hline $1-99 \%$ & & & $0.67^{\star \star}$ & \\
\hline $100 \%$ & & & $0.50^{\star \star \star \star}$ & \\
\hline \multicolumn{5}{|l|}{ Frequency injecting } \\
\hline < daily & NA & NA & 1 & NA \\
\hline daily & & & $0.47^{\star \star \star}$ & \\
\hline >daily & & & $0.38^{\star \star \star}$ & \\
\hline
\end{tabular}

$\star, \mathrm{p}<0.05 ;{ }^{\star \star}, \mathrm{p}<0.01 ;{ }^{\star \star \star}, \mathrm{p}<0.001$; GEE was used for significance testing, using a logistic link function; calendar year was forced into the models; NA, not applicable. †OR expressed per five year increase in calendar year. $¥ \mathrm{OR}$ expressed per category of years (see methods). §For injecting transitions, current behaviours were measured at the last cohort visit preceding the transition. For prevalence of current injecting, they were measured at the same visit as current injecting. $\mid$ Reference group is no use of drug.
The time trends in the main outcomes were adjusted for the changes over time in the population structure (that is, age, sex, HIV serostatus, nationality, ethnicity, prostitution, school drop out, homelessness, daily methadone use, and for injecting cessation also for duration of injecting), number of cohort visit and interval between consecutive visits: the results did not change (data not shown). There were no interactions between calender year and these variables, indicating that trends were similar in subgroups. Because of the small number of injecting initiates $(n=34)$, the adjusted model for initiation did not converge. However, if a logistic link function was used instead of a linear link the declining trend remained significant (see also table 3). Adjustment of trends in the additional injecting and non-injecting behaviours shown in table 2 also gave similar results.

It was estimated which part of the trend in the prevalence of current injecting can be explained by selection mechanisms. Of 996 participants, $446(45 \%)$ had not paid a visit in 1998 and can therefore be considered as drop outs. Reasons for drop out were: death $(n=171)$, refused further participation $(n=56)$, migration $(n=89)$, and no known reason $(n=129)$. The crude decline in current injecting is $29.5 \%$ (from $66 \%$ to $36 \%$ ). Simulation of visits of participants, who were lost to follow up, assuming continuation of last reported injecting behaviour, resulted in a decline of $19.8 \%$ (from $66 \%$ to $46 \%$, fig 2 ). Drop out can, therefore, account maximally for 33\% (1-19.8/ 29.5) of the crude decline in current injecting. If visits of participants were selected who were not lost to follow up (visit in 1997-98), a decline of $24.0 \%$ was observed (from $60 \%$ to $36 \%)$. Using this last method, drop out accounts for $19 \%$ of the total reduction in current injection (1-24.0/29.5). 


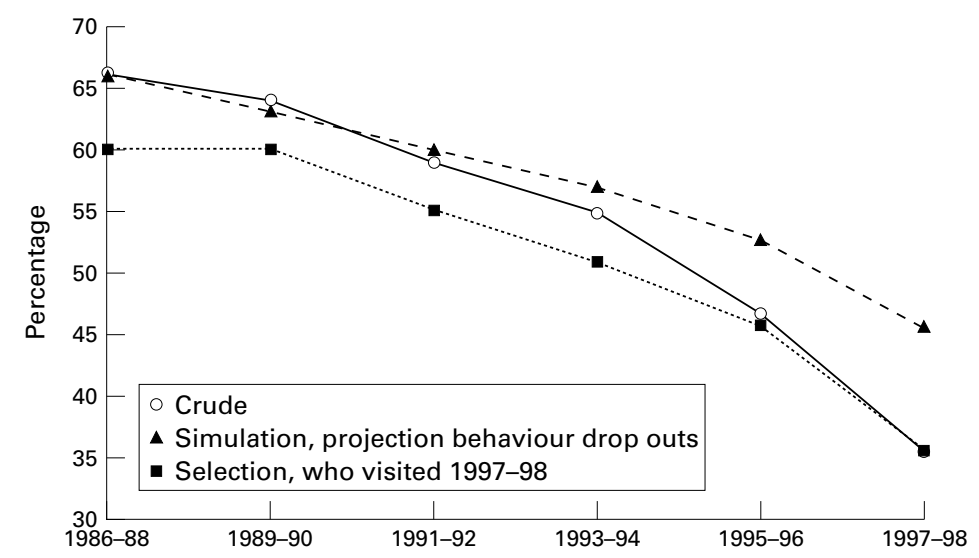

Figure 2 Trends in the prevalence of current injecting among 996 drug users participating in the Amsterdam Cohort Study.

Table 3 shows independent and significant determinants of the four outcome variables. With regard to prevalent injecting, all univariately significant determinants seemed to be independent predictors. The associations with heroin, cocaine and tranquiliser use were relatively weak, whereas sociodemographics were stronger predictors.

With regard to initiation of injection, five independent determinants were identified. The effects of all predictors were fairly strong, and there was an inverse dose-effect relation between age and injecting initiation. Variables univariately but not multivariately associated with initiation were high frequency of cocaine use and prostitution (data not shown).

There were six independent predictors of the incidence of cessation of injecting, the effects of drug use behaviours being most pronounced. The effect of having been diagnosed with AIDS is relatively strong, but the overall impact is modest given the small proportion of cohort visits $(2.3 \%)$ of participants who have been diagnosed with AIDS. Additional variables, only significant in univariate analyses, exhibiting a higher likelihood of cessation are short duration of injecting, non-Dutch nationality, alcohol use, and non-injecting cocaine use (data not shown).

Five variables were independently associated with relapse into injecting. Three exhibited a dose-effect relation: the likelihood of relapse decreased with older age and longer time since cessation of injecting, and increased with a longer duration of injecting. The effect of tranquiliser use was non-linear: only drug users who used tranquilisers less than daily have an increased risk. Variables only univariately significant with higher risk of relapse were male gender, initiation of injecting at younger age, HIV seropositivity, and frequent alcohol use (data not shown).

\section{Discussion}

The main result of this study is that there is a large and exponential decline in injecting behaviour in the Amsterdam Cohort Study. This is mainly the result of trends in individual behaviour changes - that is, an exponential increase in cessation of injecting and a linear decrease in relapse into injecting. Cessation of
KEY POINTS

- Injecting drug use among Amsterdam drug users has halved, mainly because of individual behaviour changes.

- Non-injecting cocaine use has strongly increased among Amsterdam drug users.

- Needle exchange programmes do not increase injecting behaviour.

- Reduction of injecting seems possible.

injecting often fails, but the balance of the dynamic process of cessation and relapse is towards a growing proportion succeeding in long term cessation, a long duration of cessation being associated with a smaller likelihood of relapse. Initiation of injecting has also declined significantly, but the absolute number of new initiates was already low in the late 1980 s so that this trend is relatively less important. Study drop out, indicating selective mortality and migration, could explain at most $33 \%$ of the injecting prevalence decline. This is considered a maximum as several drug users lost to follow up will have stopped injecting too, especially as drop out may be related to cessation of injecting or drug use in general (abandoning their old life with social contacts to prevent relapse)..$^{39}$

Some comments are needed concerning the generalisibility of the findings. Firstly, current injectors are strongly overrepresented in the cohort, and the mean age is relatively high. The observed prevalence of injecting in 1998 of $36 \%$ may be twofold lower in Amsterdam, according to unpublished estimates of the Municipal Health Service in Amsterdam. However, trends and risk factors are more generalisible than point estimates of prevalence and incidence measures. All trends remained significant after adjustment for changes in the study population. Secondly, there may be a sizeable subgroup of young injectors who are not in contact with the health care system nor with (older) drug users, for example, young users of cocaine or synthetic drugs in the dance scene. Such a group would not be connected to the regular street scene, as in a 1998 survey in Amsterdam among regular illicit drug users aged 30 or less, only a small proportion currently injected (van Ameijden, manuscript in preparation). Also, only 32 current injectors aged 25 or less could be identified in Amsterdam after an extensive search (snowballing/chain referral, nomination techniques, and health care system). ${ }^{40}$ Thirdly, a possible effect attributable to the counselling component of the cohort study is controlled for by statistical adjustment of trends for number of cohort visit. Furthermore, the medical examinations reduce the likelihood of socially desirable responding, injection stigmata (needle tracks, abscesses, scars) easily being detected.

The prevalence of injecting in the cohort has almost halved ( $66 \%$ to $36 \%)$. This is similar to the twofold decrease in the number of needles exchanged from 1990 to $1997,{ }^{35}$ and cannot be explained by an increase in buying needles as 
we showed that consistent use of NEPs increased. Therefore, the estimated 2500 IDUs in Amsterdam in 1990, ${ }^{34}$ including foreigners, may have decreased to 1250 , the total number of drug users remaining fairly stable. As the proportion of injectors is decreasing exponentially, a substantial further decline may be expected in the near future in the absence of immigration of new IDUs. Although there was a maximum impact of AIDS prevention measures in Amsterdam among current injectors ${ }^{14}{ }^{15}$ the absolute number of overdoses and new HIV and hepatitis infections will continue to decline. This effect is strengthened by the declining proportion of recent initiates into injecting among IDUs, infectious diseases incidence being highest among recent initiates. ${ }^{41}$ Therefore, expansion of interventions targeted at prevention of injecting behaviour does not seem warranted in Amsterdam. However, there are a considerable number of former and current IDUs who have acquired HIV and hepatitis infections in the past who are in need of appropriate treatments and care.

EXPLANATORY FACTORS FOR TRENDS

With regard to effects of drug policy, it is confirmed that harm reduction, including NEPs and absence of injecting paraphernalia laws, does not lead to an increase in the number of injectors or frequency of injecting (see introduction). The Amsterdam NEPS are low threshold, large scale, and long existing. Moreover, the current incidence of initiation of injecting of $2 \%-3 \%$ per year was lower in Amsterdam than in cities with smaller scale or without NEPs and with stronger law enforcement: $10 \%$ per year in Montreal, ${ }^{42} 10 \%$ in New York, ${ }^{43}$ and $30 \%$ in China. ${ }^{27}$ However, part of these differences may be explained by a higher mean age in the Amsterdam cohort. Other authors hypothesised that injecting drug use may be an unintended consequence of strong law enforcement. ${ }^{120}$

It was found that daily methadone prescription was associated with a lower injecting prevalence, but not with injecting transitions. However, from this study no conclusions can be drawn concerning effects of methadone programmes, as data are lacking on methadone dose and control for self selection bias is poor. ${ }^{29}$ In a more sophisticated evaluation study in Amsterdam, an individually increasing methadone dose was strongly related to cessation of injecting, but the increasing trend in injecting cessation could not be explained by a community wide increase in methadone doses. ${ }^{30}$

Moreover, all trends in individual transitions remained significant when adjusted for maturing out (that is, increasing age) and other sociodemographics. Therefore, ecological factors are probably important, especially changes in drug use culture and drug market. Drug policy and law enforcement activities have not changed substantially in Amsterdam. Ecological factors were also indicated by studies showing large geographical differences in injecting prevalence. $^{212244}$ The importance of cultural factors in Amsterdam is indicated by Surinamese and Antillean drug users, who have a "needle taboo", having a lower prevalence and incidence of injecting and a higher cessation rate, whereas foreign drug users inject more often. Female drug users inject less often than male drug users, although prostitutes were found to inject more often. Ethnic and gender differences have been observed before. ${ }^{27} 4546$ Group norms and attitudes as a reason for injection cessation are identified in a qualitative study in Amsterdam, for example, perceiving injectors as "losers" who are unhealthy. ${ }^{39}$ A changing drug market is probably also important in Amsterdam: the availability of precooked cocaine (crack) recently increased while the availability of (injectable) cocaine and heroin decreased, ${ }^{47}$ prices of heroin and cocaine being relatively low (30-60 euro/ gram).

PREVENTION OF INJECTING

Prevention of injecting may be possible as injecting is not an inevitable consequence of using illicit drugs and as a growing proportion succeeded in long term cessation of injecting. Peer-based interventions may be an effective preventive measure as, in line with previous studies, ${ }^{17394849}$ the most consistent determinant for transitions was injecting behaviour of a steady sexual partner. The majority of other determinants do not seem amenable to intervention, but important determinants were not measured (see below). Several identified determinants may only reflect intermediate factors in the causal path. For instance, frequent noninjecting heroin use was the strongest predictor of injecting initiation; initiation of (frequent) heroin use seems an important step in the pathway to injecting use, as indicated in studies among amphetamine ${ }^{49}$ and crack users. ${ }^{50}$ Also, predictors of cessation - that is, high frequency of non-injecting heroin use and not attending NEPs - may indicate gradual injecting cessation and abandoning injecting users' social networks.

A recent qualitative study in Amsterdam ${ }^{39}$ showed that, although the actual reasons for injecting cessation were hardly modifiable (major health problems, inability to inject, pressure of important others, severe dependence, and cultural disapproval; similar to another in depth study ${ }^{48}$ ), the health care system can be of assistance with methods to maintain non-injecting behaviour (high dose methadone maintenance and other medication, adoption of non-injecting drug use, abandoning injecting users' social networks, and adequate housing). Relapse prevention can have a substantial effect, as we found that injecting is not a stable behaviour: $70 \%$ of cohort participants with an injecting history reported cessation for at least one four month period.

\section{NON-INJECTING COCAINE USE}

Since 1992 in the cohort study, non-injecting use of cocaine has tripled among IDUs and more than doubled among non-IDUs. At present, non-injecting use of cocaine is more frequent than of heroin. Although no systematic data were available concerning mode of 
administration (for example, snorting, smoking/free-basing; self prepared or precooked), other studies indicated that this mainly concerns cocaine base ${ }^{51}$ with a recent increase in cocaine being pre-cooked, ${ }^{47}$ that is, ready to use (comparable in its effects to crack). The study population reported on here mainly consists of older opioid dependants who have a history of methadone treatment. In an Amsterdam survey in 1998, among regular drug users aged 30 years or less, about $90 \%$ reported current use of pre-cooked cocaine use and only one in five reported current injecting (Welp et al, manuscript in preparation). As discussed earlier, ecological factors may be responsible for the increase in cocaine use, which was also suggested in other cities where cocaine use recently increased. ${ }^{19} 5253$

We thank our nurses and physicians for data collection. This study was performed as part of the Amsterdam Cohort Studies on AIDS, a collaboration between the Municipal Health Service, the Academic Medical Centre and the Central Laboratory of the Netherlands Red Cross Blood Transfusion Service, Amsterdam, the Netherlands.

Funding: this study was supported by the Netherlands Foundation for Preventive Medicine as part of the Stimulation Program on AIDS Research of the Program Committee for AIDS Research (PccAo) (grant no 28-1258).

Conflicts of interest: none.

1 Stimson GV, Adelekan M, Thodes T. The diffusion of drug injecting in developing countries. International fournal of injecting in developing cou

2 Fisher B, Kendall P, Rehm J, et al. Charting WHO-goals for licit and illicit drugs for the year 200: are we 'on track'? Public Health 1997;111:271-5.

3 van Haastrecht HJA, van Ameijden EJC, van den Hoek JAR, et al. Predictors of mortality in the Amsterdam cohort of human immunodeficiency virus (HIV)-positive and HIVnegative drug users. Am f Epidemiol 1996;143:380-91.

4 van Ameijden EJC, van den Hoek JAR, Mientjes GHC, et al. A longitudinal study on the incidence and transmission patterns of HIV, HBV and HCV infection among drug users in Amsterdam. Eur $\mathcal{F}$ Epidemiol 1993;9:255-62.

5 Spijkerman IJB, Mientjes GHC, van Ameijden EJC, et al. Risk factors for skin abcesses and endocarditis among injection drug users. F Clin Epidemiol 1996;49:1149-54.

6 van der Werf MJ, van Benthem BHB, van Ameijden EJC. Prevalence, incidence and risk factors for anemia in HIV-positive and HIV-negative drug users. Addiction 2000;

7 Dinwiddie SH, Reich T, Cloninger CR. Lifetime complications of drug use in intravenous drug users. F Subst Abuse 1992;4:13-18

8 Stiffman AR, Dore P, Earls F, et al. The influence of mental health problems on AIDS-related risk behaviors in young adults. F Nerv Ment Dis 1992;180:314-20.

9 White JM, Dyer KR, Ali RL, et al. Injecting behaviour and risky needle use amongst methadone maintenance clients. Drug Alcohol Depend 1994;34:113-19.

10 Strathdee SS, van Ameijden EJC, Mesquita F, et al. Can HIV epidemics among injection drug users be prevented? AIDS 1998;12 (suppl A):s71-9.

11 van Ameijden EJC, Watters JK, van den Hoek JAR, et al. Interventions among injecting drug users: do they work? AIDS 1995;9 (suppl A):s75-84.

12 Drucker E, Lurie P, Wodak A, et al. Measuring harm reduction: the effects of needle and syringe exchange programs and methadone maintenance on the ecology of programs and methadone maintenance
HIV. $A I D S$ 1998;12 (suppl A):s217-30. 13 Strathdee SS, Patrick DM, Currie SL, et al. Needle injecting drug use study. AIDS 1997;11:F59-65.

14 van Ameijden EJC, Coutinho RA. Maximum impact of HIV prevention measures targeted at injecting drug users. AIDS 1998;12:625-33.

15 van Ameijden EJC, Langendam MW, Notenboom J, et al. Continuing injecting risk behaviour: results from the Amsterdam cohort study among drug users. Addiction 1999;94:1051-61.

16 Garfein R, Vlahov D, Galai N, et al. Viral infections in short-term injection drug users: the prevalence of the hepatitis C, hepatitis B, human immunodefiency virus, and human T-lymphotropic viruses. Am 7 Public Health 1996;86:655-61.

17 Des Jarlais DC, Casriel C, Friedman SR, et al. AIDS and the transition to illicit drug injection - results of a randomised transition to illicit drug injection - results of a random

18 van Ameijden EJC, van den Hoek JAR, Hartgers C, et al. Risk factors for the transition from non-injection to injection drug use and accompanying AIDS risk behavior in a cohort of drug users. Am f Epidemiol 1994;139:1153-63.
19 Grund JPC, Adriaans NFP, Kaplan CD. Changing cocaine moking rituals in the Dutch heroin addict population. $\mathrm{Br}$ 7 Addict 1991;86:439-48.

20 Grund JPC, Stern LS, Kaplan CD, et al. Drug use and HIVconsequences: the effect of drug policy on patterns of everyday drug use in Rotterdam and the Bronx. Br $\mathcal{F}$ Addict 1992;87:381-92.

21 De la Fuente L, Barrio G, Royuela L, et al. The transition from injecting to smoking heroin in three Spanish cities. Addiction 1997;92:1749-63.

22 De la Fuente L, Saavedra P, Barrio G, et al. Temporal and geographic variations in the characteristics of heroin seized in Spain and their relation with the route of administration. Drug and Alcohol Dependence 1996;40:185-94.

23 Des Jarlais DC, Friedman SR, Sotheran JL, et al. Continuity and change within an HIV epidemic: injecting drug users in New York City, 1984 through 1992. FAMA 1994;271:1217 .

24 Schoenbaum EE, Hartel DM, Gourevitch MC. Needle exchange use among a cohort of injecting drug users. AIDS 1996;10:1729-34

25 Peters AD, Reid MM, Griffin SG. Edinburgh drug users: are they injecting and sharing less? AIDS 1994;8:521-8.

26 Robertson JR, Ronald P, Gilian MR, et al. Deaths, HIV infection, abstinence and other outcomes in a cohort of injecting drug users followed for 10 years. BMF 1994;309: injecting

27 Wu Z, Detels R, Zhang J, et al. Risk factors for intravenous drug use and sharing equipment among young male drug users in Longchuan County, south-west China. AIDS 1996;10:1017-24

28 van Ameijden EJC, van den Hoek JAR. AIDS among injecting drug users in The Netherlands: The epidemic and the response. In: Santfort T, ed. The Dutch response to HIV: pragmatism and consensus. London: Taylor and Francis, 1998:61-85.

29 Langendam MW, van Haastrecht HJA, van Brussel GHA, et $a l$. Differentiation in the Amsterdam methadone dispensing circuit: determinants of methadone dosage and site of methadone presription. Addiction 1998;93:61-72.

30 Langendam MW, van Brussel GHA, van Ameijden EJC Methadone maintenance and cessation of injecting drug use: results from the Amsterdam Cohort Study. Addiction 2000;95:591-600

31 Lurie P, Reingold AL, Browser B, et al. The public health impact of needle exchange programs in the united states and abroad. San Francisco: University of California, 1993.

32 Watters JK, Estilo MJ, Clark GL, et al. Syringe and needle exchange as HIV/AIDS prevention for drug users. $\mathcal{F A M A}$ 1994;271:115-20.

33 Buster M. Verslaafde opa's em oma's. Amsterdams Drug Tijdschrift 1996;13:16-17.

34 Buning EC. De GGEGD en het drugprobleem in cijfers $I V$. Amsterdam: Municipal Health Service, 1990.

35 Fennema JSA, van Ameijden EJC, Wiessing L, et al. No evidence that harm reduction approach leads to increase in injection behavior in amsterdam, 1989-1996. In: Fennema $\mathrm{H}$. HIV infection among drug users and the potential for heterosexual spread. [PhD thesis]. Amsterdam: University of Amsterdam, 1998:53-62.

36 van Ameijden EJC, van den Hoek JAR, van Haastrecht HJA, et al. The harm reduction approach and risk factors for HIV seroconversion in injecting drug users, Amsterdam. Am F Epidemiol 1992;136:236-43.

37 Zeger S, Liang KY. Longitudinal data analysis for discrete and continuous outcomes. Biometrics 1986;42:121-30.

38 Langendam MW, van Haastrecht HJA, van Ameijden EJC The validity of drug users' self-reports in a non-treatment setting: prevalence and predictors of incorrect reporting methadone treatment modalities. Int 7 Epidemiol 1999;28: 514-20.

39 Witteveen E, Langendam MW, van Ameijden EJC. Motieven voor en methoden van stoppen met spuiten onder Amsterdamse druggebruikers: Een kwalitatieve studie. Tijdschrift voor Alcohol, Drugs en andere Psychotrope Stoffen 2000;24:125-39.

40 van Aalderen $\mathrm{H}$. Jonge spuiters in Amsterdam: een systematische zoektocht. Tijdschrift voor Alcohol, Drugs en andere Psychotrope Stoffen 1997;22:266-30.

41 Fennema JSA, van Ameijden EJC, van den hoek JAR, et al. Young and recent-onset injection drug users are at higher Young and recent-onset injection drug user
risk for HIV. Addiction 1997;92:1457-65.

42 Roy E, Haley N, Boivin JF, et al. Predictors of drug injection initiation in a street youth cohort. Geneva: 12th World AIDS Conference, 1998, abstract 33389.

43 Neaigus A, Friedman SR, Hagen DL, et al. Transitions to injecting and seroconversions for HIV, hepatitis B and hepatitis C among non-injecting heroin users. Geneva: 12th World AIDS Conference, 1998, abstract 13382

44 Diaz T, Chu SY, Byers RH, et al. The types of drugs used by HIV-infected injection drug users in a multistate surveillance project: implications for intervention. Am f Public Health 1994;84:1971-5.

45 Griffiths P, Gossop M, Powis B, et al. Extent and nature of transitions of route among heroin addicts in treatmentpreliminary data from the Drug Transitions Study. $\mathrm{Br}$ Addict 1992;87:485-91.

46 Darke S, Cohen J, Ross J, et al. Transitions between routes of administration of regular amphetamine users. Addiction 1994;89:1077-83.

47 Anonymous. Het Spoor Bijster: Rondhangende jongeren op Amsterdam Centraal station. Amsterdam: Stichting Mainine, 1998. 
48 Sibthorpe B, Lear B. Circumstances surrounding needle use transitions among injection drug users: Implications for HIV intervention. International fournal of Addiction 1994;29:1245-57.

49 Crofts N, Louie R, Rosenthal D, et al. The first hit: circumstances surrounding initiation into injecting. Addiction 1996;91:1187-96.

50 Irwin KL, Edlin BR, Faruque S, et al. Crack cocaine smokers who turn to drug injection: characteristics, factors associated with injection, and implications for HIV transmission. Drug Alcohol Depend 1996;42:85-92.
51 Hartgers C, van den Hoek A, Krijnen P, et al. Changes over time in heoin and cocaine ise among injecting drug users in Amsterdam, The Netherlands, 1985-1989. Br f Addict

52 Hunter GM, Donoghoe MC, Stimson GV. Crack use and injection on the increase among injecting drug users in London. Addiction 1995;90:1397-400

53 Barrio G, De La Fuente L, Royuela L, et al. Cocaine use among heroin users in Spain: the diffusion of crack and cocaine smoking. F Epidemiol Community Health 1998;52: $172-80$.

\section{Want full text but don't have a subscription?}

\section{Pay per view}

For just \$8 you can purchase the full text of individual articles using our secure online ordering service. You will have access to the full text of the relevant article for 48 hours during which time you may download and print the pdf file for personal use.

www.jech.com 